\title{
LINE application: An alternative tool to develop writing abilities
}

\author{
Jumariati ${ }^{1}$, Emma Rosana Febriyanti ${ }^{2}$ \\ 1,2 Program Studi Pendidikan Bahasa Inggris, Fakultas Keguruan dan Ilmu Pendidikan, \\ Universitas Lambung Mangkurat, Banjarmasin, Indonesia \\ 1 jumariati01@ulm.ac.id (corresponding author) \\ 2 emma.rosana@ulm.ac.id \\ Received: October 20, 2019; \\ Accepted: February 17, 2020; \\ Published: March 11, 2020
}

\begin{abstract}
This study tried to reveal the potential use of LINE application in developing students' writing abilities through blended learning. It employed a quasiexperimental design which involved thirty-nine students of the advanced writing course. The experimental group was taught by using process and product approach combined with LINE application with teacher's and classmates' feedbacks while the control group was taught by using a conventional method without LINE application. The data were the result of students' writings collected by using a writing test and scoring rubric as the instruments. The analysis of the students' scores was carried out by employing the independent sample t-test. The finding showed that there was a significant effect of the use of LINE application on the students' writing abilities. Furthermore, the differences were found in the components of vocabulary, grammar, organization, content, and mechanics. The study concluded that LINE application was a potential tool to develop students' abilities in writing provided that it was combined with teachers' and classmates' feedback which facilitated students' writing improvement.
\end{abstract}

Keywords: social media; LINE application; writing performance; EFL students; blended learning

How to cite this paper (in APA style): Jumariati \& Febriyanti, E. R. (2020). LINE application: An alternative tool to develop writing abilities. Journal on English as a Foreign Language, 10(1), 68-83. https://doi.org/10.23971 hefl.v10i1.1566 
DOI: https: //doi.org/10.23971/jefl.v10i1.1566

cc) (i) (2)

The rapid advancement of technology has affected life and society. The discoveries of modern tools or gadgets have influenced the way people communicate in which the tools help make communication easier and faster ever than before. In this sense, the invention of mobile phones and smartphones take a very crucial role in communication in the digital era. Particularly the social media that the tools offer have been the center of people's attention since the media help them communicate easily. The ease and fastness that the tools offer have convinced people to use the gadgets in other fields such as medical, legal, marketing, and even education (Dashtestani, 2013; Raja \& Nagasubramani, 2018; Zuhri, 2016).

Along with technology development, the term "Mobile-assisted language learning (MALL)" emerges referring to a teaching and learning method which utilizes mobile phones, tablets, and smart-phones to connect teacher and students as well as establish an online class with typical activities of lesson delivery, reading, writing, and discussions (Kukulska-Hulme \& Shield, 2008; Park \& Slater, 2014; Raja \& Nagasubramani, 2018). MALL brings some pedagogical advantages which include facilitating the teaching and learning process outside the classroom by creating a platform which allows for discussion and sharing a question and answers about everything relevant to teaching and learning. A study showed that students engaged more frequently in teaching and learning outside the class and that MALL provided them with more learning opportunities and experience (Kim, Rueckert, Kim, \& Seo, 2013). Likewise, a study by Fauzan and Ngabut (2018) revealed that the students enjoyed flipped learning applied in writing class as it brought a new atmosphere of learning. The students also confirmed that they could regulate their learning easily as the flipped learning allowed them to assess materials anytime using their electronic gadgets. Meanwhile, research by Sa'diyah and Cahyono (2019) found that blogging improves students' ability in writing in which the students taught by using blogging achieved better scores than the students taught by a using conventional method. Finally, a study by Alotumi (2020) showed that students had positive perceptions of the MALL in a teaching and learning process as they found it useful and easy to use.

MALL, however, also has some limitations which make the implementation challenging (Dashtestani, 2013; Zuhri, 2016). First, not all 
teachers and students have mobile phones and smart-phones. Second, the size of the "devices" which is normally small can make some people feel uncomfortable to read the notes on the screen or type on the keyboard. Third, mobile devices have limited power and data storage. As a consequence, using the devices for tools for practicing writing skills should be adjusted in terms of data size and duration. Finally, mobile devices are depending on the Internet connection; once the connection is bad, it can ruin almost everything. However, people today mostly have a private internet connection by registering their accounts to internet broadband companies and pay a certain amount of money depending on their financial abilities. Dashtestani (2013) also mentions that along with the development of technology, challenges in using mobile phones for educational purposes can be solved in the future. In short, the drawbacks dealing with mobile devices are relatively easy to overcome.

Research has been conducted to investigate the effects of social media applications to the development of students' learning. Studies have also been carried out to reveal teachers' and students' perceptions on the application of social media in teaching and learning process. A research by Alghazo and Nash (2017) on the effect of social media usage on the students' course achievement and behavior reveals that students taught using social media "WhatsApp" showed better behavior than those in the control group with less absence and missed assignments even though no significant difference was found on the course achievement. A survey study by Li (2017) showed that social media, for instance, YouTube, Blogs, Forums, and Wikis have been widely used in teaching English either as sources of learning, media of instruction and communication, or as informal learning tools. In the same vein, research by Yudhiantara and Nuryantini (2019) showed that using Instagram helped improve the students' skills in translating and writing sentences as they practiced giving feedback to others' drafts. In conclusion, social media application can be utilized as teaching and learning tools because their features allow for continuous connection and communication. Furthermore, the trend of social media is within students' interest as they are generations who grow up in the digital era as today.

To facilitate EFL learners in developing their writing skills, it is essential to treat writing as both a process and a product. By doing so, EFL learners will have sufficient opportunities to practice writing from the first draft to the final one with the assistance from their classmates and teacher. Process writing as defined by Seow (2002) is a classroom activity that incorporates writing stages such as planning, drafting, responding, revising, editing, and sharing. Students 
need to experience each of these stages to know the process of writing before they come to the final products. Research has confirmed that experiencing these stages helps improve students' writings (Kim, 2010; Miftah, 2005; Moloudi, 2011; Rollinson, 2005).

Within the context of ELT particularly at the university level, writing is one of the skills the students have to master since they have written reports as the course assignments thesis writing as a final assignment. Writing is considered as a difficult skill for EFL or ESL students as they need to deal with the vocabulary, grammar, organization, and be knowledgeable about the topic they write (Alagozlu, 2007; Fareed, Ashraf, \& Bilal, 2016; Phakiti \& Li, 2011). Therefore, making writing becomes a lesson that students like is necessary to make them interested to learn. To do so, teachers need to apply an appropriate strategy in attracting students' interest. One of the strategies is by integrating mobile technology which offers various applications which teachers can make use in their teaching. Mobile technology is very close to students' life because they are generations who were born with technology that they are called the digital natives (Prensky, 2001).

In teaching-learning writing skills, teachers commonly apply process and product approach enabling the students to generate the idea, write the draft, read each other's draft, revise the draft and publish the writing products. By doing this, teachers engage students in active learning through writing and reviewing each other's drafts to give feedback on their classmates. Srichanyachon (2012) mentions that teachers can give direct corrective feedback and indirect corrective feedback. Indirect correction feedback only consists of the indication of errors in the students' writing, while the direct correction feedback identifies both the errors and the target form.

Studies found that giving and receiving feedback give positive contribution to the improvement of students' writings in terms of the content of the writings and the linguistic components such as the vocabulary, grammar, and mechanics (Bitchener, Young, \& Cameron, 2005; Hartono, 2014; Strijbos, Narciss, \& Dünnebier, 2010; Yu \& Wu, 2013). The notion of offering and receiving assistance in a form of feedback is in line with the theory of socio learning introduced by Vygotsky in 1978. Within this context, learners develop their Zone of Proximal Development (ZPD) by the scaffolding provided by the teacher and their classmates (Behroozizad, Nambiar, \& Amir, 2014; Helou \& Newsome, 2018; Mutekwe, 2018; Zuengler \& Miller, 2006). The corrective 
feedback offered either in direct or indirect forms helps students see the quality of their writings which may be difficult to find on their own.

In this study, the scaffolding given by the teacher and classmates is in the form of corrective feedback which enables students to move a step forward and improve their writings. It supports the concept proposed by Vygotsky in which ZPD offers social support for learners in the forms of dyadic interactions (Poehner \& VanCompernolle, 2011). Within the writing process, students offer corrective feedback to their classmates' drafts in written form followed by a discussion to confirm things to revise. In this way, they can work on their zone of proximal development.

As previously noted, students today are commonly familiar with mobile technology. Hence, utilizing mobile technology in teaching and learning especially in teaching writing seems to be potential. However, to the researchers' knowledge, studies on LINE application in the field of education have not been conducted yet. This application is probably to be used as a teaching and learning tool to teach writing in the EFL context. The main reason is that the features of the LINE application allow for its users to write their ideas and write comments to others' posts. They also can share documents either written form or audio-video. By writing down and sharing ideas, they practice writing which gradually improves their writing ability which comprises how to express ideas, ensure the connections of the idea, and use appropriate vocabulary, grammar, and mechanics. Moreover, the chat column either in the group chat or in the notes provides its users a place to share ideas in written form and have a discussion with the group members as if it is a discussion in a classroom setting.

LINE application can be implemented in the classroom blended with traditional paper and pen writing. However, implementing it outside the class will provide students more chances to practice writing. Since they are assigned to write a paragraph and post their writing in the group notes, they will have the chance to practice their writing skills anytime they want to. Moreover, when they are urged to read others' posts and give feedback, they will apply their knowledge on writing conventions such as the organization, grammar, vocabulary, and mechanics to evaluate their friends' posts. In this way, they make the best use of their mobile phones for learning outside class hours.

Referring to the research gap previously discussed, it is necessary to conduct a study to examine the potential of LINE application in a writing course. Therefore, this study tries to investigate the effect of using LINE 
application in teaching writing to the students' abilities in essay writing. Furthermore, when a significant effect is found, the investigation is proceeded to reveal on what writing components the significant effect occurs.

\section{METHOD}

This research focused on investigating the cause-effect relationship between the implementation of LINE application and the students' skills in writing. Consequently, the quasi-experiment was employed to establish the cause-and-effect relationships in schools setting where random assignment and full control cannot be carried out (Jacobs, Sorensen, \& Razavieh, 2010). The study was carried out in the English Language Education Study Program of Lambung Mangkurat University, Banjarmasin, Indonesia. The subjects of the research were the students of the Advanced Writing course from two classes (class A and class B) with the total number of thirty-nine students. The experimental group was taught by using the LINE application combined with teachers' and classmates' feedback. The LINE application was applied outside class hours to give students chances to practice writing that was expressing ideas in the form of a paragraph. In the classroom, the students continued writing the paragraph they had tried to develop in the LINE application forum into an essay. Meanwhile, the control group was taught by using a conventional method with teachers' and classmates' feedback without using the LINE application. The subjects were also taught to write an essay and given feedback from both the teacher and classmates. The only difference was they did not use LINE application outside class hours. The research applied a post-test design only; therefore, a post-test was given to both groups at the end of the treatment.

The instrument utilized to obtain the data was a writing test and scoring rubric. The prompts of the writing test were designed to direct the subjects in writing the essays. To meet the validity, the prompts were developed by referring to the course syllabus. Meanwhile, the analytical scoring rubric was developed to evaluate the students' writing abilities in terms of the content, organization, grammar, vocabulary, and mechanics. The rubric was adapted from a rubric developed by Cohen (1994). Both the writing test and the scoring rubric were validated by involving the lecturers of the Advanced Writing course as the experts in the field of teaching and assessing writing.

The instrument was tried out to the students of the Advanced Writing course of class $C$ who had similar characteristics with the subjects of the study. The try-out was aimed at measuring the validity and reliability. To measure the validity, the Pearson Product-Moment correlation was employed. The analysis 
showed that the obtained significance value for each component of writing was less than 0.05 which affirmed that the raters' scores were valid. Meanwhile, the inter-rater reliability was measured by using the Intra-class Correlation Coefficient. The result showed that the obtained reliability coefficient was .892 and thus it was considered reliable. After the treatment in the experimental group had been finished, a post-test was carried out. The result of the post-test was then analyzed by using the independent sample t-test.

The data were then analyzed to find the answers to the research questions. First, the descriptive statistic was deployed to reveal the information about the minimum and maximum score, mean, median, range, and standard deviation. After that, the independent sample t-test by using the statistical computer software of SPSS 20.0 version was employed to answer the research question of whether or not there was a significant difference in the mean scores between the students taught by using LINE application and those without LINE application. Before doing this, the assumptions of normality and homogeneity needed to be fulfilled. The analysis was carried out by using the Shapiro Wilk and Levene's test. Once the significant difference found, the effect size was calculated. Finally, the analysis was continued to each component of writing: content, organization, vocabulary, grammar, and mechanics.

\section{FINDINGS}

This part is divided into three sections which include the fulfillment of statistical assumptions, the analysis result of the effect of LINE application on students' writing ability, and the analysis result of the effect of LINE application on students' writing ability in each component of writing.

\section{Fulfillment of Assumptions of Normality and Homogeneity}

Before analyzing the data by using the independent sample t-test, the data should fulfill the assumptions of normality and homogeneity. First, the Shapiro Wilk test was carried out to fulfill the assumption of normality. The result showed that the significance level was more than 0.05 which meant that the data had a normal distribution. Then, Levene's test was conducted to fulfill the assumption of homogeneity. The test on homogeneity revealed that the $p$ value was .506 which meant that the data (the scores of control and experimental groups) were homogeneous. Table 1 displays the result of homogeneity testing. 
Table 1. The result of homogeneity of variances test

\begin{tabular}{cccc}
\hline \multicolumn{4}{c}{ Scores } \\
\hline Levene statistic & $\mathrm{df} 1$ & $\mathrm{df2}$ & Sig. \\
.447 & 1 & 76 & .506 \\
\hline
\end{tabular}

As shown in Table 1, the significance value was .506 which was higher than the significance level 0.05. This affirmed that the students were homogeneous. In other words, they had an equal ability in writing.

\section{The Effect of LINE Application on Students' Writing Ability}

The students' scores in the test were equated to find whether or not LINE application affected their writing ability. The first analysis was on the descriptive statistics of the findings. In this part, the scores on the post-test between the control and experimental groups were analyzed. To do this, SPSS version 20.0 was utilized. The findings on the descriptive statistics are displayed in Table 2.

Table 2. The descriptive statistics

\begin{tabular}{lcccccc}
\hline & N & Range & Minimum & Maximum & Mean & $\begin{array}{c}\text { Standard } \\
\text { deviation }\end{array}$ \\
\hline $\begin{array}{l}\text { Control } \\
\text { group }\end{array}$ & 39 & 24.00 & 60.00 & 84.00 & 70.87 & 5.71 \\
$\begin{array}{l}\text { Experimental } \\
\text { group }\end{array}$ & 39 & 24.00 & 64.00 & 88.00 & 76.30 & 5.32 \\
$\begin{array}{l}\text { Valid N (list- } \\
\text { wise) }\end{array}$ & 39 & & & & & \\
\hline
\end{tabular}

Table 2 shows that in the control group, the minimum score was 60 whereas the maximum score was 84 . In the experimental group, the minimum score was 64 while the maximum score was 88 . Then, the mean score of the control group was 70.87 whereas the experimental group was 76.31 . Figure 1 depicts the difference of the mean scores between the control and experimental groups.

As displayed in Figure 1, the mean score of the experimental group was higher than that of the control group. The difference of the scores was 5.44 points which affirmed that the students taught by using LINE application gained better scores on the test compared to those taught by using a conventional method.

Journal on English as a Foreign Language, 10(1), 68-83

Copyright (C) 2020 by JEFL, p-ISSN 2088-1657; e-ISSN 2502-6615 


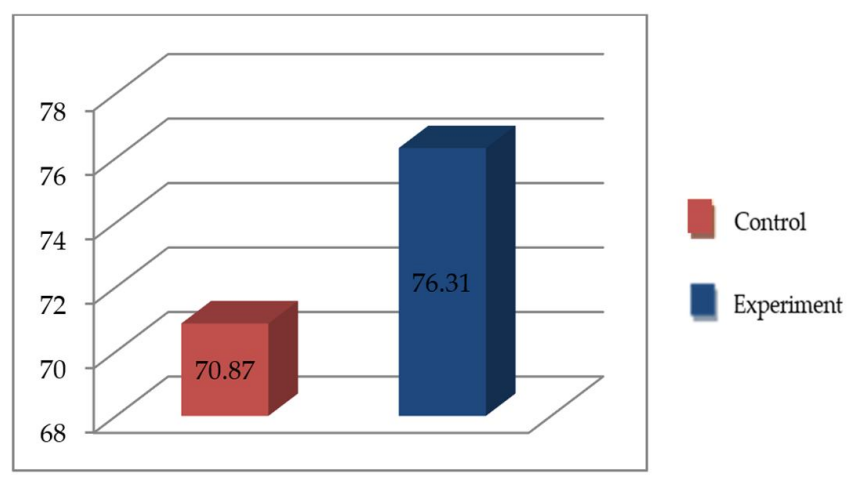

Figure 1. The mean scores of control and experimental groups

To find the statistical difference in the students' scores, the independent sample t-test was employed. The analysis was carried out to test the null hypothesis which states that "there is no significant difference in the mean scores between the control and experimental groups". The analysis was carried out by using t-test since the data were homogeneous.

Meanwhile, hypothesis testing was conducted by using the independent sample t-test and the result is shown in Table 3.

Table 3. The result of hypothesis testing

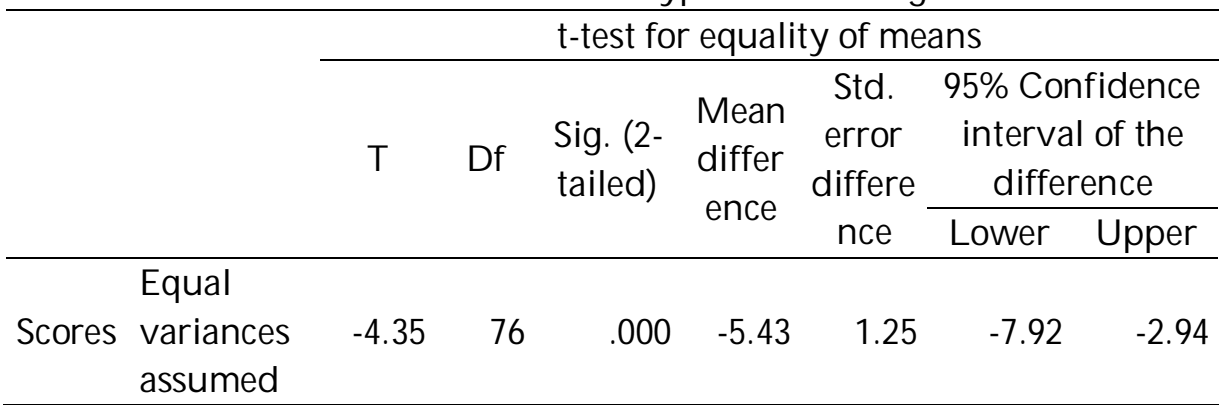

As depicted in Table 3, the $p$ value was .000 which was less than the significance level .05. Therefore, there was not enough evidence to accept the null hypothesis. This was to say that there was a significant effect on the use of LINE application on the students' abilities in writing.

The next analysis was to measure the effect size to reveal how large is the effect of using LINE application to the students' ability in writing: small, medium, or large. The measurement was carried out by using Cohen's $\mathrm{d}$ formula since the number of samples of both groups was equal. The result showed that the effect size value was 0.49 which meant that the effect was 
medium. This was to say that the use of the LINE application had a medium effect on the students' ability in writing.

\section{The Effect of LINE Application on the Students' Writing Ability in Each Component of Writing}

The next analysis was on each component of writing to find what component the difference was found to be significant. The data are summarized in Table 4.

Table 4. The results on each component

\begin{tabular}{cccccc}
\hline \multirow{2}{*}{ Groups } & \multicolumn{5}{c}{ Writing components } \\
\cline { 2 - 6 } & Content & Organization & Vocabulary & Grammar & Mechanics \\
\hline Control & 17.25 & 15.7 & 14.25 & 12 & 9.63 \\
Experiment & 17.58 & 17.2 & 16.13 & 13.88 & 9.88 \\
\hline
\end{tabular}

Table 4 shows that mean scores in each component of writing in the experimental group were higher than those in the control group. To provide a clearer picture of the differences, in Figure 2 it is displayed.

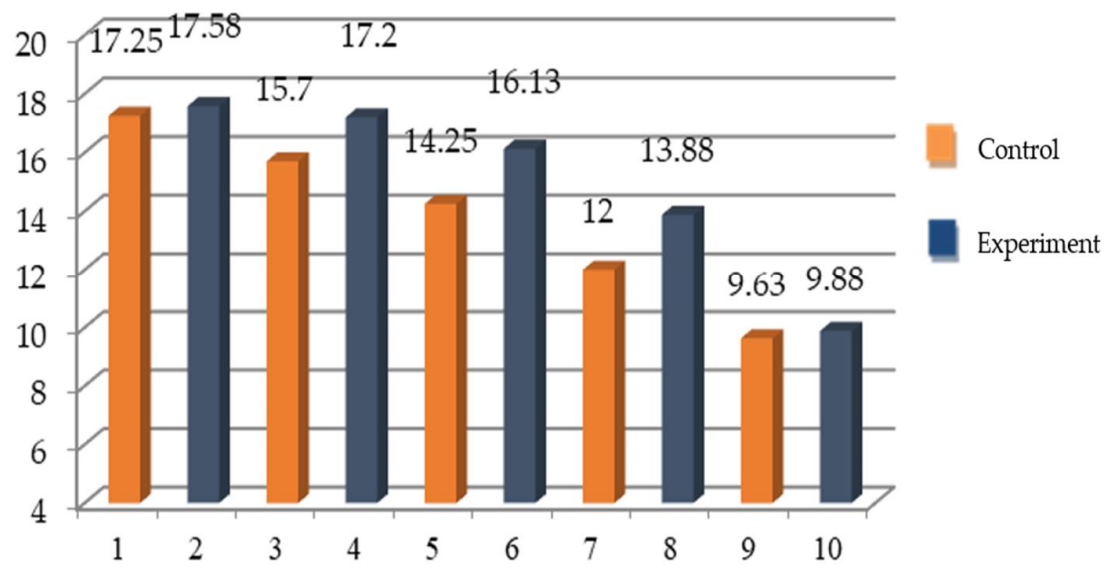

Figure 2. The mean scores in each component of control and experimental groups

Based on the data displayed in Figure 2, the mean scores in every component in the experimental group were higher than those in the control group. For content, the increasing difference achieved 0.33 points; whereas in the organization the difference was 1.5 points. Then, in the component of vocabulary and grammar, the difference increased up to 1.88 points. Finally, the difference in the component of mechanics was 0.25 points. Hence, the highest

Journal on English as a Foreign Language, 10(1), 68-83

Copyright @ 2020 by JEFL, p-ISSN 2088-1657; e-ISSN 2502-6615 
difference was on the components of vocabulary and grammar while the least was on the mechanics.

To conclude, the use of LINE application in the teaching and learning of the Advanced Writing Course affected the students' writing abilities with regards to the vocabulary, grammar, organization, content, and mechanics consecutively.

\section{DISCUSSION}

The findings of the study showed that there was a significant effect of the use of LINE application on the students' ability in writing essays. There are some possible reasons for the significant effect of LINE application which is elaborated below.

First, the LINE application offers a platform for students to practice expressing ideas in written forms, give feedback on their friends' writings and receive feedback regarding the components of writing. As noted previously, writing is a process in which students need to go through before they can produce a good piece of writing (Seow, 2002). Hence, utilizing the LINE application can provide them the chance to write the draft of their essay which is in the form of a short paragraph that they will develop later in the classroom. This confirms the theory and research findings by Kim (2010), Miftah (2005), Moloudi (2011), and Rollinson (2005) that process writing facilitates students in learning writing as they have sufficient chance to write the draft, revise the drafts, and edit the draft.

Further, the subjects of this research received feedback from their classmates and lecturer. The feedbacks were in the form of comments and symbols regarding the things they should improve. The feedback helped them improve their draft since they were told the parts which are still not proper and they need to revise. As previous studies pointed out, giving and receiving feedback can help students improve their writings (Hartono, 2014; Strijbos et al., 2010; Yu \& Wu, 2013) since the feedback shows them which parts they need to improve. If they were to read and revise on their own, it would be uneasy for them to spot the errors in their writings. Hence, receiving feedback is beneficial to them.

This idea of giving feedback is in line with the notion of social learning proposed by Vygotsky in 1978 that students learn to develop their Zone of Proximal Development (ZPD) with the help from the teacher and their 
classmates (Behroozizad et al., 2014; Zuengler \& Miller, 2006). This is to say that having others read their drafts and show the errors for them helps to ease them in revising their drafts. Particularly, when they obtained feedback in the type of indirect corrective feedback such as underlines, circles, or other codes, they became aware of the errors. These symbols told them that some revisions need to be made. Based on the classroom observations, when the students had troubles in interpreting the codes, they asked the reviewer for confirmation and asked the lecturer for help. After that, they revised their drafts on their own. By doing this, they learned with the help of their classmates and teacher which steadily helped them developed their writing ability.

As noted, the feedback that the students obtained either from their classmates or the lecturer during LINE sessions and class hours seemed to contribute to their writing improvement. During the discussion in the LINE group, they were required to read each other's writings and gave responses regarding the content, organization, vocabulary, grammar, and mechanics. This means they practiced to become critical readers and gave indirect corrective feedback to their classmates. Later on, they practiced to critically think when they write on their own by considering whether or not their writings follow writing conventions. The implementation of the LINE application as a medium of practicing writing is beneficial. Students who were familiar with this application found it easy to access and friendly-use. This was to say that the use of social media in education particularly in EFL writing brought benefits to students' learning as previous research has revealed (Alghazo \& Nash, 2017; Li, 2017; Sa'diyah \& Cahyono, 2019). As pointed out by Sa'diyah and Cahyono (2019), using blogging in writing class helped students improved their scores in writing as they had a sufficient chance to practice writing. Likewise, using WhatsApp, Twitter, and Facebook in the studies also contributed to the improvement of students' writing abilities.

When the data is examined closely, that is on each component of writing, the increase is apparent in the vocabulary and grammar whereas the least is in the component of mechanics. The reasonable causes are the corrective feedbacks provided by their classmates were mostly about the appropriate words (diction) and the grammar to use. The majority of the students wrote the correct forms of diction and grammar which eventually helped their classmates improve their draft quality. Later on, when they wrote individually, they applied the knowledge by carefully chose the appropriate diction to express their ideas and applied correct grammar. This finding is similar to the finding of a study by (Hartono, 2014) which found that the most frequent feedback offered 
and used in the EFL writing classroom is feedback on the grammar while the least is mechanics. The subjects of his research made frequent errors in these components, the same as the subjects of this study.

The positive finding of the present study is also found in the study by Sa'diyah and Cahyono (2019) revealing that the students taught using blogging achieved better scores in writing than those taught using the conventional method. Practicing writing through blogging provided the students with the chance to improve their writing abilities and focus on the content. Another research by Yudhiantara and Nuryantini (2019) found that the use of Instagram enhanced the students' interaction through peer feedback. The study confirmed that giving and receiving feedback from their peers could improve their writing and translating skills.

Hence, the findings of this study confirmed the findings of previous studies which revealed that the use of social media in writing helped students improve their writing ability. This study also confirmed the theory and previous research that incorporating process and product approach in writing facilitated students' learning improvement as they had the chance to write the draft, revise their draft, and edit their draft. Moreover, this research asserted the theory and previous studies that receiving and giving feedback in writing class is beneficial since students were helped by their classmates and teacher until they gradually developed their writing ability.

\section{CONCLUSION}

It can be concluded that using the LINE application brings a significant effect on students' writing. The increasing scores occur in all writing components under investigation which include the vocabulary, grammar, organization, content, and mechanics consecutively. The findings also indicate that corrective feedback given to students' writings in LINE application affect them in improving their drafts during writing practices. Referring to the findings of the study, it is suggested to teachers of EFL writing to incorporate LINE application in their writing practices. This is not only to increase students' motivation and performance in writing but also to make the best use of mobile technology particularly in the field of education. Further research is recommended to investigate other potential use of LINE application in teaching and learning other language skills. Involving larger subjects of research is also recommended to confirm the potential use of this application as a prospective teaching and learning tool.

Journal on English as a Foreign Language, 10(1), 68-83

Copyright @ 2020 by JEFL, p-ISSN 2088-1657; e-ISSN 2502-6615 


\section{REFERENCES}

Alagozlu, N. (2007). Critical thinking and voice in EFL writing. Asian EFL Journal, 9 (3), 118-136. Retrieved from https://www.asian-efljournal.com/main-journals/critical-thinking-and-voice-in-efl-writing

Alghazo, Y. M., \& Nash, J. A. (2017). The effect of social media usage on course achievement and behaviour. Journal of Education and Practice, 8(2), 161167.

Alotumi, M. (2020). EFL learning beyond the wall with MALL: college students' perceptions. In R. Ahmed, A. Al-kadi, T. Hagar, \& A. Scheg (Eds.), Enhancements and Limitations to ICT-Based Informal Language Learning: Emerging Research and Opportunities (pp. 138-160). doi: 10.4018/978-17998-2116-8

Bitchener, J., Young, S., \& Cameron, D. (2005). The effect of different types of corrective feedback on ESL student writing. Journal of Second Language Writing, 14, 191-205. https://doi.org/10.1016/j.jslw.2005.08.001

Behroozizad, S., Nambiar, R. M. K., \& Amir, Z. (2014). Sociocultural theory as an approach to aid EFL learners. The Reading Matrix, 14(2), 217-226.

Cohen, A. D. (1994). Assessing language ability in the classroom (2nd edition). Boston Massachuetts: Heinle \& Heinle Publishers.

Dashtestani, R. (2013). Implementing mobile-assisted language learning (MALL) in an EFL context: Iranian EFL teachers' perspectives on challenges and affordances. The JALT CALL Journal, 9(2), 149-168.

Fareed, M., Ashraf, A., \& Bilal, M. (2016). ESL learners' writing skills: Problems, factors and suggestions. Journal of Education $\mathcal{E}$ Social Sciences, 4(2), 83-94. doi: 10.20547 亿ess0421604201

Fauzan, A., \& Ngabut, M. N. (2018). EFL students' perception on flipped learning in writing class. Journal on English as a Foreign Language, 8(2), 115-129. https://doi.org/10.23971 „jefl.v8i2.792

Hartono, H. (2014). Online peer feedback in EFL writing class: How it improves students' writing and the problems the students face. Paper Presented in the 8th International Conference of Developing Educational Professionals in South East Asia. Retrieved from https://www.researchgate.net/publication/329164207

Helou, M., \& Newsome, L. K. (2018). Application of Lev Vygotsky's sociocultural approach to foster students' understanding and learning performance. Journal of Education and Culture Studies, 2(4), 347-355. https://doi.org/10.22158/jecs.v2n4p347 
Jacobs, D. A., Sorensen, L. C., \& Razavieh, C. A. (2010). Introduction to research in education ( $8^{\text {th }}$ ed.). Belmont, C.A: Nelson Education, Ltd.

Kim, B. G. (2010). Collaborative discussion and peer review activity in computer-mediated EFL writing. Multimedia-Assisted Language Learning, 13(2), 105-128. http://dx.doi.org/10.15702/mall.2010.13.2.105

Kim, D., Rueckert, D., Kim, D.-J., \& Seo, D. (2013). Students' perception and experiences of mobile learning. Language Learning and Technology, 17(3), 52-73. Retrieved from http://lt.msu.edu/issues/october2013/kimetal.pdf

Kukulska-Hulme, A., \& Shield, L. (2008). An overview of mobile assisted language learning: From content delivery to supported collaboration and interaction. ReCALL, 20(3), 271-289. https://doi.org/10.1017/50958344008000335

Li, V. (2017). Social media in English language teaching and learning. International Journal of Learning and Teaching, 3(2), 148-153. https://doi.org/10.18178/ijlt.3.2.148-153

Miftah, M. Z. (2005). Enhancing writing skill through writing process approach. Journal on English as a Foreign Language, 5(1), 9-24. https://doi.org/10.23971/jefl.v5i1.88

Prensky, M. (2001). Digital natives, digital immigrants. In 5: Vol. 9. On the Horizon (pp. 1-6). Retrieved from https://doi.org/10.1108/10748120110424816

Raja, R., \& Nagasubramani, P. C. (2018). Impact of modern technology in education. Journal of Applied and Advanced Research, 3(1), 33-35. http://dx.doi.org/10.21839 jaar.2018.v3iS1.165

Rollinson, P. (2005). Using peer feedback in the ESL writing class. ELT Journal, 59(1), 23-30. https://doi.org/10.1093/elt/cci003

Sa'diyah, I. H., \& Cahyono, B. Y. (2019). Effect of project-based learning through blogging on EFL students' writing ability. Journal on English as a Foreign Language, 9(2), 199-216. https://doi.org/10.23971/jefl.v9i2.1341

Seow, A. (2002). The writing process and process writing. In J. C. Richard \& W. A. Renandya (Eds.), Methodology in Language Teaching: An Anthology of Currrent Practice (pp. 315-320). Cambridge: Cambridge University Press.

Srichanyachon, N. (2012). Teacher written feedback for L2 learners' writing development. Journal of Social Sciences, 12(1), 7-17. Retrieved from https://so02.tci-thaijo.org/index.php/hasss/article/view /7149

Strijbos, J.-W., Narciss, S., \& Dünnebier, K. (2010). Peer feedback content and sender's competence level in academic writing revision tasks: Are they critical for feedback perceptions and efficiency? Learning and Instruction, 20(4), 291-303. https://doi.org/10.1016/.learninstruc.2009.08.008 
Yu, F-Y., \& Wu, C. P. (2013). Predictive effects of online peer feedback types on performance quality. Educational Technology and Society, 16(1), 332-341.

Yudhiantara, R. A., \& Nuryantini, A. Y. (2019). Promoting mobile collaborative language learning in Islamic higher education. Journal on English as a Foreign Language, 9(2), 87-106. https://doi.org/10.23971/jefl.v9i1.961

Zuengler, J., \& Miller, E. R. (2006). Cognitive and sociocultural perspectives: Two parallel SLA worlds? TESOL Quarterly, 40(1), 35-58. doi: $10.2307 / 40264510$

Zuhri, F. (2016). Mobile assisted language learning: The recent application of emerging mobile technologies. JURNAL BASTRA, 3(1), 1-10.

\section{Authors' Brief CV}

Jumariati teaches at the English Language Education Study Program of FKIP Lambung Mangkurat University in Banjarmasin, South Kalimantan. Her particular interests are in teaching writing, materials development, and assessment in ELT. She actively involves in both national and international seminars, workshops and conferences.

Emma Rosana Febriyanti is a lecturer of English Language Education Study Program, FKIP Lambung Mangkurat University in Banjarmasin, South Kalimantan. Her interests are in TEFL, teaching speaking and grammar skills, innovation in teaching media, and English for specific purposes. 